\title{
Analisis Pengaruh Work-Life Balance Terhadap Kepuasan Kerja
}

\author{
Winanto Nawarcono, ${ }^{1)}$ Agus Setiono ${ }^{2)}$ \\ ${ }^{1,2)}$ Manajemen, STIE Nusa Megarkencana \\ 1)email: wnawarcono@gmail.com \\ ${ }^{2)}$ email: magussetiono@gmail.com
}

\begin{abstract}
Working is the main goal of someone in achieving self-actualization of their potential. Life in the workplace, work and family, work and personal fulfillment, work and social life, all illustrate the problem of a harmonious and balanced arrangement between work and other lives. In addition, the balance of employees at work and living quality of life is also the focus of company attention that will make employees more satisfied in carrying out each work. The company realizes the success of employees in working through achieving targets with exceptional performance, not solely because of the skills and competencies that employees have, but equally important is the balance of the employee in managing his personal quality of life with work demands. This research is a quantitative descriptive study. To measure the effect of Work-life Balance on Job Satisfaction, multiple linear regression methods are used with 55 respondents. The results of research that have been carried out that the variables in this study consisted of PLIW and WIPL which were stated to have a significant effect, as well as PLEW and WEPL which were stated to have no significant effect 91,4\% of the Job Satisfaction of English Jogja Homes.
\end{abstract}

Keywords: Self-Actualization, Work-life Balance, Job Satisfaction.

\section{A. PENDAHULUAN}

Sumber daya manusia memiliki peranan penting sebagai faktor penentu keberhasilan organisasi dalam mencapai kesuksesan. Penelitian ini meneliti tentang sumber daya manusia di Rumah Inggris Jogja yang mempunyai peran penting bagi siswanya dalam menyediakan dan menyampaikan materi-materi yang berkualitas, Oleh karena itu dibutuhkan karyawan yang memiliki kualitas yang baik dan memiliki kinerja yang optimal. Hal tersebut harus didukung dengan situasi kerja yang kondusif serta merespon kebutuhan karyawan dalam bekerja. Rumah Inggris Jogja berusaha selalu memberikan pelayanan yang prima kepada konsumenya dan dapat terus bertahan dalam persaingan usaha yang semakin ketat. Rumah Inggris Jogja juga membuat berbagai macam program kursus agar para konsumen leluasa memilih layananya tersebut. Permasalahan yang dimiliki Rumah Inggris Jogja salah satunya adalah mempunyai perputaran (turnover) karyawan yang cukup tinggi yaitu: 
Tabel 1

Data Turn Over Karyawan

\begin{tabular}{cc}
\hline Tahun & Jumlah \\
\hline 2018 & 32 \\
2019 & 21 \\
2020 & 27 \\
\hline
\end{tabular}

Sumber: Data Primer 2020

Dalam grafik diatas pada tahun 2018 karyawan Rumah Inggris Jogja yang mutasi berjumlah 32 orang, pada tahun 2019 berjumlah 21 orang dan pada tahun 2020 sebanyak 27 orang. Melihat latar belakang masalah di atas, peneliti tertarik untuk melakukan telaah ilmiah yang berjudul "Analisis Pengaruh Work-life Balance Terhadap Kepuasan Kerja".

\section{B. KAJIAN LITERATUR DAN TEORI}

\section{Kajian Teori}

\section{Pengertian Sumber Daya Manusia}

Dalam pengertian sumber daya manusia (Nawawi (2017)) membagi dalam dua pengertian. Pertama: pengertian sumber daya manusia secara makro adalah semua orang sebagai penduduk dan warga negara suatu negara atau dalam batas wilayah tertentu yang telah memasuki usia angkatan kerja, baik yang sudah maupun belum memperoleh pekerjaan.Kedua, pengertian sumber daya manusia secara mikro adalah semua orang yang bekerja atau menjadi anggota suatu organisasi yang disebut pegawai, karyawan, personil, pekerja atau tenaga kerja. Jadi, sumber daya manusia (SDM) adalah semua orang yang terlibat dan bekerja untuk mencapai tujuan suatu perusahaan.

\section{Pengertian Work Life Balance.}

Work-life balance adalah keadaan dimana seseorang dapat mengatur dan membagi antara tanggung jawab pekerjaan, kehidupan keluarga dan tanggung jawab lainnya. Kondisi tersebut membantu agar tidak terjadi konflik antara kehidupan pribadi dengan pekerjaan. Kesimpulannya, adalah suatu kondisi di mana seorang pekerja bisa mengatur waktu dan energi yang seimbang antara pekerjaan, kebutuhan pribadi, rekreasi, dan kehidupan berkeluarga. Dengan memiliki worklife balance, seseorang dapat menjadi lebih produktif. Hal ini karena kondisi yang dirasakan orang tersebut cukup mendukung dan meningkatkan kepuasannya dalam melakukan pekerjaan. Selain itu, ia juga menjadi lebih kreatif karena memiliki waktu, energi, atau modal lebih untuk melakukan hal yang ia senangi. 
Sebaliknya, jika seseorang tidak memiliki work-life balance yang baik, kinerjanya cenderung merosot dan bisa merusak bidang kehidupan lainnya. Umumnya, hal ini disebabkan oleh tingginya tuntutan pekerjaan zaman sekarang. Dapat dikatakan individu yang memperhatikan antara keseimbangan kehidupan kerja dan kehidupan pribadi merupakan individu yang lebih mementingkan kesejahteraan psikologisnya daripada mengejar kekayaan semata. (Westman, Brough, \& Kalliath, 2009).

Menurut Fisher (2010), terdapat empat dimensi work-life balance, yaitu: (a) Work Interference With Personal Life (WIPL), dimensi ini mengacu sejauh mana pekerjaan dapat mengganggu kehidupan individu secara pribadi, (b) Personal Life Interference With Work (PLIW), dimensi ini mengacu pada sejauh mana kehidupan individu mengganggu kehidupan pekerjaannya secara pribadi, (c) Personal Life Enhancement Of Work (PLEW), dimensi ini mengacu pada sejauh mana kehidupan seseorang dapat meningkatkan performa individu dalam dunia kerja secara pribadi, (d) Work Enhancement Of Personal Life (WEPL), dimensi ini mengacu pada sejauh mana pekerjaan bisa meningkatkan kualitas kehidupan individu secara pribadi.

\section{Pengertian Kepuasan Kerja.}

Kepuasan kerja menurut Abdurrahmat (2009) merupakan suatu bentuk sikap emosional pribadi yang menyenangkan dan mencintai pekerjaannya. Kepuasan kerja ialah kepuasan yang dapat dinikmati dalam pekerjaan dengan mendapatkan hasil dari pencapaian tujuan kerja, penempatan, perlakuan dan suasana lingkungan kerja yang baik. Karyawan yang dapat menikmati kepuasan kerja dalam pekerjaan ini, akan memilih untuk lebih mengutamakan pekerjaannya daripada balas jasa/ upah yang ia dapatkan dari pekerjaan tersebut. Karyawan akan merasa lebih puas apabila balas jasanya sebanding dengan hasil kerja yang dilakukan.

\section{Kerangka Berpikir.}

Kerangka berpikir merupakan sintesa tentang hubungan antar variabel yang telah dideskripsikan dan disusun berdasarkan dari berbagai teori, setelah itu dianalisis secara kritis dan sistematis, sehingga menghasilkan sintesa tentang hubungan variabel tersebut dan digunakan untuk merumuskan hipotesis (Sugiyono, 2017). Kerangka berpikir dalam penelitian ini adalah sebagai berikut. 


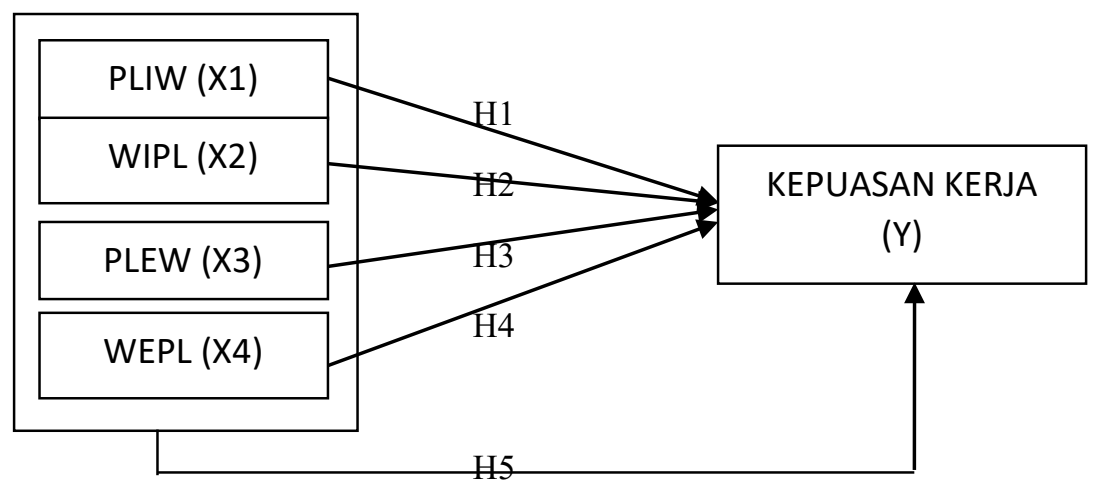

Gambar 1. Kerangka Pemikiran

\section{METODE PENELITIAN}

\section{Jenis Penelitian}

Metode penelitian yang digunakan adalah penelitian deskriptif kuantitatif dengan menggunakan pendekatan studi kasus. Metode kuantitatif adalah metode untuk menganalisis data yang dilakukan dengan cara mengumpulkan, menganalisis dan menginterprestasikan data dalam bentuk angka-angka untuk mengetahui pengaruh work-life balance terhadap kepuasan kerja pada Rumah Inggris Jogja.

\section{Jenis Data}

Jenis data dalam penelitian ini adalah data kualitatif, berisi data-data kondisi perusahaan seperti latar belakang perusahaan, struktur organisasi, visi misi dan tujuan perusahaan, berupa data-data yang diperoleh secara lisan maupun tulisan. Sedangkan data kuantitatif, yaitu data-data yang berbentuk dokumen, daftar atau angka-angka yang dapat dihitung berupa tabulasi data.

\section{Populasi}

Menurut (Sugiyono, 2017), menyatakan bahwa populasi diartikan sebagai wilayah generalisasi atas objek atau subjek yang mempunyai kualitas dan karakteristik tertentu yang ditetapkan untuk dipelajari dan ditarik kesimpulannya. Populasi dalam penelitian ini adalah seluruh karyawan pada Rumah Inggris Jogja

\section{Sampel}

Menurut (Sugiyono, 2017), menyatakan bahwa sampel merupakan bagian dari jumlah dan karakteristik yang dimiliki oleh populasi terebut. Jumlah sampel merupakan keseluruhan dari populasi yaitu sebanyak 55 responden. 


\section{Teknik Pengumpulan data}

Dalam penelitian ini teknik pengumpulan data yang digunakan oleh peneliti menggunakan metode dokumentasi, observasi dan kuesioner.

\section{Metode Analisis Data}

Metode analisis data dalam penelitian ini adalah bertujuan untuk menganalisis data-data suatu penelitian dari hasil penarikan sampel dan pengumpulan data akan diperoleh data kasar dapat dibaca dan di interpretasikan, maka dibutuhkan adanya metode analisis data.

a. Uji Instrumen, dalam penelitian ini menggunakan Uji Validitas dan Reliabilitas.

b. Uji Asumsi Klasik, data yang telah diperoleh harus memenuhi kriteria dalam uji asumsi klasik sebelum dilakukannya analisis data.. Penelitian ini menggunakan 4 uji asumsi klasik yaitu uji multikolinieritas, uji autokorelasi, uji heteroskedasitas dan uji normalitas.

c. Uji Analisis Regresi Berganda

Data yang dianalisis dengan regresi merupakan data kuantitatif yang memiliki skala pengukuran minimal interval, untuk mengetahui besarnya pengaruh variabel bebas terhadap variabel tidak bebas. Model persamaan regresi linier berganda :

$\mathrm{Y}=\alpha+\beta 1 \mathrm{X} 1+\beta 2 \mathrm{X} 2+\beta \mathrm{n} \mathrm{Xn}+\mathrm{e}$

Keterangan:

$\mathrm{Y}=$ Variabel terikat yaitu Kepuasan Kerja

$\mathrm{X}=$ Variabel bebas yaitu Work-life Balance Meliputi

$\mathrm{X} 1=\mathrm{WIPL}$

$\mathrm{X} 2=\mathrm{PLIW}$

$\mathrm{X} 3=\mathrm{PLEW}$

$\mathrm{X} 4=\mathrm{WEPL}$

$\alpha=$ Konstanta.

$\beta=$ Slope atau Koefisien estimate.

1. Uji Hipotesis

a. Uji-t (Pengujian Secara Parsial)

Untuk mengetahui ada atau tidaknya hubungan yang signifikan. Pengambilan keputusan dengan cara membandingkan P Value dengan tingkat signifikan. Tingkat signifikan yang digunakan sebesar 5\% $(\alpha: 0,05)$. Adapun kriteria penerimaan atau penolakan Ho adalah sebagai berikut:

- Ho ditolak jika $p$ value $\leq \alpha$ atau $p$ value $\leq 0,05$

- Ho diterima jika $p$ value $>\alpha$ atau $p$ value $>0,05$

b. Uji F (Pengujian Secara Simultan)

Uji F ini dilakukan bertujuan untuk mengetahui pengaruh semua variabel 
independen yang terdapat di dalam model secara bersama-sama (simultan) terhadap variabel dependen. Adapun kriteria uji $\mathrm{F}$ berdasarkan $\mathrm{P}$ value adalah sebagai berikut:

- Jika $\mathrm{P}_{\text {value }}>(\alpha: 0,05)$, maka hipotesis 0 atau $\mathrm{H}_{0}$ diterima, yang berarti tidak ada pengaruh antara variabel independen secara bersama-sama terhadap variabel dependen secara signifikan.

- Jika $\mathrm{P}_{\text {value }}<(\alpha: 0,05)$ maka hipotesis 0 atau $\mathrm{H}_{0}$ ditolak, yang berarti ada pengaruh antara variabel independen secara bersama-sama terhadap variabel dependen secara signifikan

\section{c. Koefisien Determinasi $\left(\mathbf{R}^{2}\right)$}

Koefisien determinasi $\left(\mathbf{R}^{2}\right)$ dipergunakan untuk mencari besaran persentase kontribusi variabel bebas WIPL, PLIW, PLEW, dan WEPL terhadap Kepuasan Kerja di Rumah Inggris Jogja dengan berdasarkan nilai R square dari hasil pengujian melalui SPSS. Nilai $\mathrm{R}^{2}$ ( $R$ square) adalah menunjukkan seberapa besar persentase kontribusi variabel PLIW, WIPL, PLEW dan WEPL terhadap kepuasan kerja.

\section{HASIL PENELITIAN DAN PEMBAHASAN}

\section{HASIL PENELITIAN}

a. Uji Validitas

Uji validitas dilakukan terhadap variabel independen work-life balance meliputi PLIW, WIPL, PLEW, WEPL dan variabel dependen yaitu kepuasan kerja. Hasil uji validitas untuk masing-masing variabel, dimana butir pernyataan dinyatakan valid apabila nilai korelasi ( $\mathrm{r}$ hitung) lebih besar dari nilai ( $\mathrm{r}$ tabel) dengan derajat kebebasan $\mathrm{df}=\mathrm{n}-2$ tingkat signifikan $\alpha=0,05$ diperoleh dari $\mathrm{r}$ tabel $=0,265$. Berdasarkan tabel $r$ hitung lebih besar dari pada $r$ tabel sehingga semua butir dinyatakan valid sesuai dengan hasil yang ditunjukkan di Tabel 2 dibawah ini.

b. Uji Reliabilitas

Hasil perhitungan uji reliabilitas adalah reliabel bila koefisien alphanya lebih besar dari $r$ tabel dan diatas nilai kritis 0,6 artinya dapat dipercaya dan dapat digunakan untuk penelitian. Instrumen yang bila digunakan beberapa kali untuk mengukur objek yang sama, akan menghasilkan data yang sama. Dimana syarat minimal suatu instrumen dikatakan reliabel adalah jika mempunyai nilai $\alpha>0,6$ sebaliknya jika mempunyai nilai $\alpha<0,6$ maka suatu instrumen dikatakan tidak reliabel (Imam Ghozali, 2016). Dari hasil analisis data menunjukkan bahwa semua variabel mempunyai cronbacht's alpha lebih dari 0,6 , sehingga dengan demikian dapat disimpulkan bahwa semua variabel dalam kuesioner ini adalah reliabel. 
c. Uji Asumsi Klasik

\section{Multikolinieritas}

Uji ini untuk mendeteksi ada tidaknya gejala multikolinieritas dalam regresi yaitu dengan cara melihat nilai tolerance dan variance inflating factor (VIF). Berdasarkan analisis data, hasil uji multikolinieritas untuk nilai tollerance diatas 0,1 dan nilai VIF dibawah 10 sehingga model regresi tidak terjadi multikolinieritas.

\section{Autokorelasi}

Uji autokorelasi dilakukan untuk mengetahui ada atau tidaknya penyimpangan asumsi klasik autokorelasi, yaitu korelasi yang terjadi antara residual pada satu pengamatan ke pengamatan lainnya pada model regresi.

Berdasarkan analisis data, nilai DW 2,011, selanjutnya nilai ini akan kita bandingkan dengan nilai tabel signifikansi 5\%, jumlah sampel $\mathrm{N}=55$ dan jumlah variabel $(K=5)$, maka diperoleh nilai dU 1,7681. Nilai DW 2,011 lebih besar dari batas atas (dU) yakni 1,7681 dan kurang dari (4-du) 4-1,7681=2,2319, sehingga dapat disimpulkan bahwa tidak terdapat autokorelasi.

\section{Heteroskedastisitas}

Uji heteroskedastisitas dilakukan untuk mendeteksi atas masalah heteroskedastisitas dapat dilakukan dengan melihat grafik sebaran nilai residual yang berstandarisasi. Apabila sebarannya tidak membentuk pola tertentu, baik bergelombang, melebar atau menyempit, maka dapat disimpulkan tidak terjadi heteroskedas. Hasil analisis data terlihat sebarannya tidak membentuk pola tertentu sehingga tidak terjadi masalah heteroskedastisitas atau tidak terjadi kesamaan varian.

\section{Uji Normalitas}

Uji normalitas dilakukan untuk menguji apakah distribusi variabel terikat untuk setiap nilai variabel bebas tertentu berditribusi normal atau tidak. Uji normalitas dapat dilakukan dengan melihat tabel hasil uji normalitas. Jika nilai Sig $>0,05$ maka, data berdistribusi normal. Jika nilai sig $<0,05$ maka data berdistribusi tidak normal. Hasil analisis data, nilai Asymp. Sig. adalah 0.874, lebih besar dari 0,05, maka dapat disimpulkan data berdistribusi normal.

d. Analisis Regresi Linier Berganda

Analisis regresi linier berganda dilakukan untuk mengetahui besarnya pengaruh variabel work-life balance (PLIW, WIPL, PLEW, WEPL) terhadap variabel kepuasan kerja. 
Tabel 2

Koefisien Regresi

\begin{tabular}{|c|c|c|c|c|c|}
\hline \multirow[t]{2}{*}{ Model } & \multicolumn{2}{|c|}{$\begin{array}{l}\text { Unstandardized } \\
\text { Coefficients }\end{array}$} & \multirow{2}{*}{$\begin{array}{c}\begin{array}{c}\text { Standardized } \\
\text { Coefficients }\end{array} \\
\text { Beta } \\
\end{array}$} & \multirow[t]{2}{*}{$\mathrm{T}$} & \multirow[t]{2}{*}{ Sig. } \\
\hline & $\mathrm{B}$ & Std. Error & & & \\
\hline (Constant) & 1,564 & 2,685 & & ,583 &, 563 \\
\hline PLIW & 1,845 &, 160 & ,834 & 11,557 &, 000 \\
\hline WIPL & 313 &, 155 &, 148 & 2,016 & 049 \\
\hline PLEW & ,015 &, 073 & ,008 & ,199 & ,843 \\
\hline WEPL &, 013 &, 071 &, 007 &, 182 &, 856 \\
\hline
\end{tabular}

Sumber: Data primer diolah 2020

Analisis regresi berdasarkan tabel diatas diperoleh persamaan regresi sebagai berikut:

$\mathrm{Y}=1,564+1,845 \mathrm{X}_{1}+0,313 \mathrm{X}_{2}+0,015 \mathrm{X}_{3}+0,013 \mathrm{X}_{4}$

Hasil persaman regresi tersebut adalah nilai konstanta sebesar 1,564, menunjukkan bahwa jika tidak ada variabel work-life balance (PLIW, WIPL, PLEW, WEPL), maka besarnya nilai kepuasan adalah 1,564. Sedangkan untuk masing-masing koefisien regresi dapat dijelaskan sebagai berikut:

1) Koefisien variabel PLIW $(1,845)$, maksudnya jika ada penambahan terhadap variabel PLIW sebesar 1 dalam satuan $\%$, maka kepuasan kerja akan bertambah sebesar $1,845 \%$ dengan anggapan variabel yang lain adalah tetap.

2) Koefisien variabel WIPL (0,313), maksudnya jika ada penambahan terhadap variabel WIPL, sebesar 1 dalam satuan \%, maka kepuasan kerjaakan bertambah sebesar $0,313 \%$ dengan anggapan variabel yang lain adalah tetap.

3) Koefisien variabel PLEW $(0,015)$, maksudnya jika ada penambahan terhadap variabel PLEW sebesar 1 dalam satuan \%, maka kepuasan kerja akan bertambah sebesar $0,015 \%$ dengan anggapan variabel yang lain adalah tetap.

4) Koefisien variabel WEPL $(0,013)$, maksudnya jika ada penambahan terhadap variabel WEPL sebesar 1 dalam satuan $\%$, maka kepuasan kerja akan bertambah sebesar 0,013\% dengan anggapan variabel yang lain adalah tetap.

e. Uji Hipotesis

Untuk menguji hipotesis penelitian digunakan uji t dan uji $F$, dimana uji $t$ untuk membuktikan pengaruh secara parsial dan uji $\mathrm{F}$ untuk membuktikan pengaruh secara simultan atau bersama-sama.

\section{1) Uji t}

Uji t digunakan untuk mengetahui pengaruh variable work-life balance yaitu; PLIW (X1), WIPL (X2), PLEW (X3), WEPL (X4), terhadap kepuasan 
kerja (Y) secara parsial. Berdasarkan dugaan sementara terhadap hipotesis penelitian yang menyatakan hipotesis diterima atau ditolak. Pelaksanaan pengujian ini peneliti menggunakan uji t dengan ketentuaan tarif signifikansi alpa $5 \%(0,05)$.

Variabel PLIW $\left(\mathrm{X}_{1}\right)$

Hasil perhitungan variabel PLIW memiliki t hitung sebesar 11,557 dengan taraf signifikan atau $P_{\text {value }} 0.000$ dengan $\alpha=0,05$, maka nilai signifikan $P_{\text {value }}$ lebih kecil dari $\alpha$ berarti PLIW berpengaruh signifikan terhadap kepuasan kerja di Rumah Inggris Jogja.

Variabel WIPL $\left(\mathrm{X}_{2}\right)$

Hasil perhitungan variabel WIPL $\left(\mathrm{X}_{2}\right)$ memiliki t hitung sebesar 2,016 dengan taraf signifikan atau $P_{\text {value }} 0,049$ dengan $\alpha=0,05$, maka nilai signifikan $P_{\text {value }}$ lebih kecil dari $\alpha$ berarti WIPL berpengaruh signifikan terhadap kepuasan kerja di Rumah Inggris Jogja.

Variabel PLEW $\left(\mathrm{X}_{3}\right)$

Hasil perhitungan variabel PLEW (X3) memiliki t hitung sebesar 0,199 dengan taraf signifikan atau $P_{\text {value }} 0,843$ dengan $\alpha=0,05$, maka nilai signifikan atau $\mathrm{P}_{\text {value }}$ lebih besar dari $\alpha$ berarti variabel PLEW tidak berpengaruh signifikan terhadap kepuasan kerja di Rumah Inggris Jogja.

Variabel WEPL $\left(\mathrm{X}_{4}\right)$

Hasil perhitungan variabel WEPL (X4) memiliki t hitung sebesar 0,182 dengan taraf signifikan atau $P_{\text {value }} 0,856$ dengan $\alpha=0,05$, maka nilai signifikan $\mathrm{P}_{\text {value }}$ lebih besar dari $\alpha$. Berarti variabel WEPL tidak berpengaruh signifikan terhadap kepuasan kerja di Rumah Inggris Jogja.

\section{2) Uji F}

Digunakan untuk mengetahui apakah terdapat hubungan yang nyata antara variabel independen $(\mathrm{X})$ dengan variabel dependen $(\mathrm{Y})$ secara bersama-sama, hasil uji $\mathrm{F}$ yang telah dilakukan dengan menggunakan program SPSS diperoleh hasil sebagai berikut:

Tabel 3

Nilai F hitung variabel

ANOVA $^{\mathrm{a}}$

\begin{tabular}{llrrrrl}
\hline & Model & Sum of Squares & df & Mean Square & F & Sig. \\
\hline 1 & Regression & 2592,411 & 4 & 648,103 & 144,042 &, $000^{\mathrm{b}}$ \\
& Residual & 224,971 & 50 & 4,499 & & \\
\hline & Total & 2817,382 & 54 & & & \\
\hline
\end{tabular}

Sumber: Data primer diolah 2020 
Berdasarkan Tabel 9 di atas dapat diketahui bahwa nilai $\mathrm{F}$ hitung sebesar 144.042 dengan signifikan 0,000 sedang $\alpha=0,05$ karena $P_{\text {value }}$ lebih kecil dari $\alpha=0,05$ berarti variabel work-life balance PLIW, WIPL, PLEW, WEPL secara bersama-sama berpengaruh positif dan signifikan terhadap kepuasan kerja Rumah Inggris Jogja.

\section{Koefisien Determinasi $\left(\mathbf{R}^{2}\right)$}

Koefisien determinasi dipakai untuk mencari besaran persentase kontribusi variabel bebas PLIW, WIPL, PLEW, WEPL terhadap kepuasan kerja di Rumah Inggris Jogja dengan melihat nilai R square

\section{Tabel 4}

Koefisien Determinasi

\begin{tabular}{ccccc}
\hline Model & $\mathrm{R}$ & R Square & $\begin{array}{c}\text { Adjusted R } \\
\text { Square }\end{array}$ & $\begin{array}{c}\text { Std. Error of } \\
\text { the Estimate }\end{array}$ \\
\hline 1 &, $959^{\mathrm{a}}$ &, 920 &, 914 & 2,121 \\
\hline
\end{tabular}

Sumber: Data primer diolah 2020

Nilai $\mathrm{R}^{2}$ ( $R$ square) sebesar 0,920 menunjukkan bahwa persentase kontribusi variabel work-life balance (PLIW, WIPL, PLEW, WEPL) terhadap kepuasan kerja karyawan di Rumah Inggris Jogja sebesar 92,0\%, sedangkan 8,0\% sisanya dipengaruhi oleh variabel lain yang tidak terdapat dalam penelitian.

\section{PEMBAHASAN}

Berdasarkan hasil analisis diatas, maka dapat diambil beberapa pembahasan sebagai berikut:

a. Pengaruh PLIW (X1)

Hasil penelitian ini menunjukkan bahwa variabel Personal Life Interference Work (PLIW) berpengaruh terhadap kepuasan kerja pada Rumah Inggris Jogja, Hasil perhitungan variable PLIW memiliki t hitung sebesar 11,557 dengan taraf signifikan atau $P_{\text {value }} 0.000$ dengan $\alpha=0,05$, maka nilai signifikan $P_{\text {value }}$ lebih kecil dari $\alpha$ berarti PLIW berpengaruh signifikan terhadap kepuasan kerja di Rumah Inggris Jogja.

b. Pengaruh WIPL (X2)

Hasil pengujian variabel Work Interference Personal Life (WIPL) menunjukkan pengaruh signifikan. Hasil perhitungan variabel WIPL $\left(\mathrm{X}_{2}\right)$ memiliki t hitung sebesar 2,016 dengan taraf signifikan atau $P_{\text {value }} 0.049$ dengan $\alpha=0,05$, maka nilai signifikan $\mathrm{P}_{\text {value }}$ lebih kecil dari $\alpha$ berarti WIPL berpengaruh terhadap kepuasan kerja di Rumah Inggris Jogja.

c. Pengaruh PLEW (X3)

170 .:. $\quad$ Jurnal Solusi, Volume 16, Nomor 2, Desember 202I | P 1907-2376, E 2797-8699 
Hasil perhitungan variabel (PLEW) memiliki t hitung sebesar 0.199 dengan taraf signifikan atau $P_{\text {value }} 0.843$ dengan $\alpha=0,05$ maka nilai signifikan atau $P_{\text {value }}$ lebih besar dari $\alpha$ berarti variabel PLEW tidak berpengaruh terhadap kepuasan kerja di Rumah Inggris Jogja.

d. Pengaruh WEPL (X4)

Hasil perhitungan variabel (WEPL) $\left(\mathrm{X}_{4}\right)$ memiliki t hitung sebesar 0, 182 dengan taraf signifikan atau $P_{\text {value }} 0,856$ dengan $\alpha=0,05$, maka nilai signifikan $P_{\text {value }}$ lebih besar dari $\alpha$. Berarti variabel WEPL tidak berpengaruh terhadap kepuasan kerja di Rumah Inggris Jogja.

e. Variabel yang Paling Dominan

Hasil penelitian menunjukkan bahwa variable $\mathrm{X}_{1}, \mathrm{X}_{2}, \mathrm{X}_{3}$ dan $\mathrm{X}_{4}$ diperoleh hasil bahwa variabel PLIW $X_{1}(11,557)$, WIPL $X_{2}(2,016)$, PLEW $X_{3}(0,199)$ dan variabel WEPL $\mathrm{X}_{4}(0.182)$.

Dengan demikian dapat disimpulkan bahwa variable PLIW $\mathrm{X}_{1}(11,557)$ yang paling dominan atau paling besar pengaruhnya terhadap kepuasan kerja di Rumah Inggris Jogja dibandingkan dengan variable WIPL $X_{2}(2.016)$, PLEW $X_{3}(0.199)$, dan WEPL X $_{4}(0.182)$

\section{E. KESIMPULAN DAN SARAN}

\section{Kesimpulan}

Berdasarkan hasil pembahasan, maka dapat kesimpulan sebagai berikut:

a. Variabel Personal Life Interference Work (PLIW) memiliki pengaruh signifikan terhadap kepuasan kerja pada Rumah Inggris Jogja.

b. $\quad$ Variabel Work Interference Personal Life (WIPL) memiliki pengaruh signifikan terhadap kepuasan kerja pada Rumah Inggris Jogja.

c. Variabel Personal Life Enhancement of Work (PLEW) tidak memiliki pengaruh signifikan terhadap kepuasan kerja pada Rumah Inggris Jogja.

d. Variabel Work Enhancement of Personal Life (WEPL) tidak memiliki pengaruh signifikan terhadap kepuasan kerja pada Rumah Inggris Jogja.

e. Berdasarkan hasil analisis pembahasan diketahui bahwa nilai $\mathrm{F}$ hitung sebesar 144.042 dengan signifikan 0,000 , karena diketahui bahwa $\mathrm{P}_{\text {value }}$ lebih kecil dari $\alpha=0,05$ berarti variabel Work-Life Balance (PLIW, WIPL, PLEW, WEPL) secara bersama-sama berpengaruh positif dan signifikan terhadap kepuasan kerja Rumah Inggris Jogja.

Dari hasil analisis diketahui bahwa nilai $\mathrm{R}^{2}$ ( $R$ square) diketahui sebesar 0,920 menunjukkan bahwa persentase kontribusi variabel Work-Life Balance (PLIW, WIPL, PLEW, WEPL) terhadap kepuasan kerja di Rumah Inggris Jogja sebesar 92,0\%, sedangkan $8,0 \%$ sisanya dipengaruhi oleh variabel lain yang tidak diteliti dalam penelitian. 


\section{Winanto Nawarcono, Agus Setiono}

\section{Saran}

a. Bagi Rumah Inggris Jogja peneliti menyarankan perlunya lebih memperhatikan aspek yang berkaitan dengan Work-Life Balance, terutama Personal Life Interference Work (dimensi ini mengacu sejauh mana pekerjaan dapat mengganggu kehidupan individu secara pribadi) dan Personal Life Interference With Work (dimensi ini mengacu pada sejauh mana kehidupan individu mengganggu kehidupan pekerjaannya secara pribadi, serta meningkatkan kegiatan yang mendukung terciptanya Work-Life Balance yang semakin baik agar menghasilkan kepuasan kerja karyawan dan meningkatkan kualitas kerja karyawan itu sendiri, yang pada akhirnya akan meningkakan kinerja organisasi.

b. Untuk penelitian selanjutnya dapat menambah variabel-variabel lain yang tidak di teliti dalam penelitian ini, dan faktor-faktor lain yang mendukung dalam peningkatan Work-Life Balance serta kepuasan kerja karyawan dalam bidang sumber daya manusia.

\section{REFERENSI}

Abdurrahmat. 2009. Manajemen Sumber Daya Manusia. Rineka. Cipta. Alex S. Nitisemito. Bandung.

Abdus. 2014. Manajemen Insani Dalam Bisnis. Pustaka Pelajar. Yogyakarta.

Achmad, et al. 2010. Metodologi Penelitian Sumber Daya Manusia. Penerbit UINMaliki Press (Anggota IKAPI). Malang.

Andriani, Prima. 2017. Pengaruh dimensi-dimensi work-life balance terhadap keterlekatan karyawan generasi $x$ dan $y$ di Indonesia. Universitas Pertanian Bogor. Bogor.

Anwar, Prabu. 2013. Manajemen Sumber Daya Manusia Perusahaan. PT. Remaja Rosdakarya. Bandung.

Bangun. 2012. Manajemen Sumber Daya Manusia. Erlangga. Jakarta.

Delecta, P. 2011. WorkLife Balance. International Jurnal of Current Research.

Fisher, Bulger., Smith. 2010. Beyond work and family: a measure of work/nonwork interference and enhancement. Journal of Occupational Health Psychology.

Ganapathi, I Made. D. 2016. Pengaruh work-life balance terhadap kepuasan kerja karyawan PT Bio Farma Persero. Universitas Telkom. Bandung.

Ghozali, Imam. 2016. Aplikasi Analisis Multivariate dengan Program SPSS: Badan Penerbit UNDIP. Semarang.

Hadari, Nawawi. 2017. Perencanaan SDM Untuk Organisasi Profit yang Kompetitif. UGM Press. Yogyakarta.

Hadi, Sutrisno. 2013. Metodologi Penelitian. Andi. Yogyakarta.

Hasibuan, Melayu S.P. 2017. Manajemen Sumber Daya Manusia. Bumi Aksara. Jakarta. 
Hudson. 2010. The case for work-life balance. Australia: Hudson Highland Group.

Indriantoro., Supomo. 2014. Metodologi Penelitian Bisnis Untuk Akuntansi dan Manajemen. BPFE. Yogyakarta.

Kaswan. 2015. Pengembangan Sumber Daya Manusia. Alfabeta. Bandung.

Kuncoro, Mudrajad. 2013. Metode Riset untuk Bisnis \& Ekonomi. Erlangga. Jakarta.

Moedy, D. M. 2013. Analisis Work-life Balance, Keinginan untuk Meninggalkan Organisasi, Kepenatan (Burnout) dan Kepuasan Kerja pada Dosen Universitas Atma Jaya Yogyakarta. Skripsi, Universitas Atma Jaya, Program Studi Manajemen Fakultas Ekonomi. Yogyakarta.

Muhid. 2012. Analisis Statistik. Zifatama. Sidoarjo.

Purwati, Putrie Dwi. 2016. Pengaruh keseimbangan kehidupan kerja (work-life balance) terhadap beban kerja (work load) divisi penjualan di PT Ulam Tiba Halim (marimas) cabang sidoarjo. UIN Malik Ibrahim. Malang.

Qodrizana, Diah Lailatul. 2018. Pengaruh work-life balance terhadap kepuasan kerja studi pada karyawan perempuan yayasan insan permata tunggul wulung kota malang. Universitas Brawijaya. Malang.

Robbins, Stephen. P., Marry Coutler. 2016. Human Resources Management. Selemba Empat. Jakarta

Schermerhorn, John R. 2013. Management, 12th ed. New Jersey: John Wiley \& Sons, Inc.

Singh, Preeti, Khanna, Parul. 2011. Work-Life Balance a Tool for Increased Employee Productivity and Retention. Lachoo Management Journal.

Sondang. 2015. Manajemen Sumber Daya Manusia. Bumi Aksara. Jakarta.

Spector, P. E. 2012. Industrial and organizational psychology: Research and practice 6th Ed. New Jersey: John Wiley \& Sons, Inc

Sugiyono. 2017. Metode Penelitian. Alfabeta. Bandung.

Suparno. 2015. Manajemen Pengembangan Sumber Daya Manusia. Pustaka Pelajar. Yogyakarta.

Supriyanto, Achmad. S., Maharani, Vivin. 2013. Metodologi Penelitian

Manajemen Sumberdaya Manusia. UIN-Maliki Press. Malang.

Uma, Sekaran. 2014. Metodologi Penelitian untuk Bisnis. Salemba Empat. Jakarta.

Wahyuni, Edr, Sri. 2018. Pengaruh keseimbangan kehidupan kerja (work-life balance) dan kepuasan kerja terhadap loyalitas pegawai dan guru. Universitas Sumatra Utara. Medan. 
